\title{
Kuantum Mekaniksel Sıra Değiştirme Bağıntılarının Bir Optik Deneyi Yoluyla Öğretimi
}

\author{
A. Alper BÍLLUR ${ }^{1}$, Serkan AKKOYUN ${ }^{2}$, Murat BURSAL ${ }^{3}$ \\ ${ }^{\text {I} C u m h u r i y e t ~ U ̈ n i v e r s i t e s i, ~ F e n ~ F a k u ̈ l t e s i, ~ F i z i k ~ B o ̈ l u ̈ m u ̈, ~ Y u ̈ k s e k ~ E n e r j i ~ v e ~ P l a z m a ~ F i z i g ̆ i ~ A n a b i l i m ~ D a l,, ~ 58140, ~}$ \\ Sivas \\ ${ }^{2}$ Cumhuriyet Üniversitesi, Să̆llk Hizmetleri Meslek Yüksek Okulu, Tibbi Hizmetler ve Teknikleri Bölümü, \\ 58140,Sivas
}

${ }^{3}$ Cumhuriyet Üniversitesi, Eğitim Fakültesi, İlköğretim Bölümü, Fen Bilgisi Eğitimi Anabilim Dal, 58140, Sivas

\section{Özet}

Heisenberg belirsizlik ilkesi ile doğrudan ilişkili olan kuantum mekaniksel sıra değiștirme bağıntıları, öğrencilerin kuantum mekaniğini anlamaları açısından büyük bir öneme sahiptir. Lisans programlarında genellikle teorik olarak verilen, modern fizik ve kuantum fiziği derslerinde kullanılan işlemci formalizmi, çoğu kez soyut olarak kalmakta ve öğrenciler tarafindan yeterince anlaşılamamaktadır. Bu çalışma kapsamında, kuantum mekaniksel olguların geometrik optik araçları vasıtasıyla incelenebileceğinden yola çıkılarak sıra değiștirme bağıntılarının deneysel bir yöntem kullanılarak somutlaştırılması ve bu yolla daha kolay ve kalıcı öğrenmelerin sağlanması hedeflenmiştir. Deney içeriği ve matematiksel formalizm, çalışma içerisinde konuyla ilgili referans kitaplarla ilişkilendirilerek açıklanmıştır. Çalışma kapsamında kullanılan deney araçlarının kolay erişilebilir ve ekonomik olmalarına özen gösterilmiştir. Bu deneyin, kuantum fiziği içerikli derslerin verildiği başta fizik, fizik öğretmenliği ve fen bilgisi öğretmenliği programları olmak üzere, ilgili laboratuar uygulamalarında ve teorik dersleri destekleyen gösteri deneyi formatında kullanılabileceği düşünülmektedir.

Anahtar Kelimeler: Fizik Eğitimi, Kuantum Fiziği, Heisenberg Belirsizlik İlkesi, Kuantum Mekaniksel İşlemci, Sıra Değiştirme Bağıntısı, Işığın Kutuplanması.

\section{Teaching Quantum Mechanical Commutation Relations via an Optical Experiment}

\begin{abstract}
The quantum mechanical commutation relations, which are directly related to the Heisenberg uncertainty principle, have a crucial importance for understanding the quantum mechanics of students. During undergraduate level courses, the operator formalisms are generally given theoretically and it is documented that these abstract formalisms are usually misunderstood by the students. Based on the idea that quantum mechanical phenomena can be investigated via geometric optical tools, this study aims to introduce an experiment, where the quantum mechanical commutation relations are represented in a concrete way to provide students an easy and permanent learning. The experimental tools are chosen to be easily accessible and economic. The experiment introduced in this paper can be done with students or used as a demonstrative experiment in laboratory based or theory based courses requiring quantum physics content; particularly in physics, physics education and science education programs.
\end{abstract}

Keywords: Physics Education, Quantum Physics, Heisenberg Uncertainty Principle, Quantum Mechanical Operator, Commutation Relation, Light Polarization.

Sorumlu yazar/Corresponding author: Serkan AKKOYUN Tel: 05057101354, e-posta:sakkoyun@ cumhuriyet.edu.tr 


\section{Giriş}

Bilim tarihinde, Antik Yunan biliminin zirvelerinden biri olarak kabul edilen ve İslam Dünyası'nda da Muallim-i Evvel (İlk Öğretmen) olarak adlandırılan Aristoteles'in fizikle ilgili açıklamaları deneysel verilerle desteklenmemiş olmasına rağmen, yüzyıllar boyunca hakim olan fizik görüşü olarak bilim dünyasında etkisini hissettirmiştir. Bu yaygın ve etkin fizik anlayışı, ancak, Dehalar Çağı olarak adlandırılan 17. yy.'da, modern anlamda ilk fizikçi olarak kabul edilen Galileo ve klasik fiziğin zirvesi olarak kabul edilen Newton tarafindan köklü bir biçimde değiştirilebilmiştir [1]. Newton'un diferansiyel ve integral hesap tekniklerini yetkin bir biçimde kullanarak yazdığı ve Kepler'in gezegenlerin çekim yasalarının matematiksel ispatını içeren bilim tarihinin en ünlü kitaplarından olan Doğa Felsefesinin Matematiksel İlkeleri [Principia] [2], bu yeni fizik anlayışının çok önemli bir başarısı olmuştur [3]. Öyle ki, zaman içinde Lagrange, Laplace, Paskal ve Euler gibi 18. yy.'1n önemli matematikçilerinin de katkıları ile Newton mekaniğinin evrendeki fiziksel her olayı tam ve net olarak açıklar hale geldiği kabul edilmiştir. Bu determinist düşünce, evrenin bir makine gibi işlediğini ve bu makineye ait herhangi bir parça için, kesin ve net tahminlerin her an yapılabileceğini öngörmektedir $[1,4]$.

19. yy.'da periyodik cetvelin oluşturulmasından ve Neptün gezegeninin astronomlar tarafindan keşfinden önce, bu gezegenin matematiksel olarak yerinin ve büyüklüğünün hesaplanmış olması örneğine benzer olaylar, klasik fizik açısından nihai zaferler olarak kabul edilmiştir. Üstelik bu zaferlerle, fiziğin son sınırlarına gelindiği öne sürülmeye başlanmıştır [1]. Oysaki 20. yy. ile birlikte, Planck'ın siyah cisim 1şıması üzerinde yaptığı çalışmalar sonucunda ortaya attığı kuantum fiziği kuramı, klasik fiziğin birçok temel kabullenimi ile farklı bulgular ortaya koymaktadır.

Klasik fizikte gözlenebilir nicelikler (ölçülebilirler), ölçüm yapan kişinin ölçümünden bağımsızdır. Bir parçacığın konumunun ve hızının, aynı anda ve kesin bir doğrulukla ölçülebileceğini söyleyen klasik mekanik, bu anlamda deterministiktir. Örneğin, güneş sisteminde Mars gezegeninin, herhangi bir andaki konumu ve hızı bilinebiliyorsa, Newton hareket denklemleri kullanarak, gezegenin daha sonraki bir andaki konumu ve momentumu, gözlem yapan kişiden bağımsız olarak, aynı anda tam bir doğrulukla hesaplanabilir. Bu düşünce tarzı, kuantum mekaniğinde, temelden değişikliğe uğramıştır. Görüngüsel olarak, güneş sistemine benzeyen, çekirdek ve elektronlardan oluşan atomik sistemde, elektronların konum ve hızlarını tam bir doğrulukla, aynı anda belirlemek mümkün değildir [5].

Klasik fiziğin deneysel olarak açıklayamadığı, 1şığın dalga/tanecik ikililiği özelliği veya atomunun elektronlarının hareketi gibi konularda, kuantum fiziği yoluyla deneysel verilerle uyumlu açıklamalar ortaya konulmuştur. Bu süreçte klasik fizikteki determinizm düşüncesine zıt olarak, kuantum fiziğinin önemli bir kilometre taşı olan Belirsizlik İlkesi, 1927 yılında ortaya atılmıştır [6,7]. Bu ilkeye göre, konum ve hız gibi birbirleriyle ilişkili iki fiziksel nicelik, aynı anda ve kesin doğrulukta ölçülemez [8]. Belirsizlik ilkesi, Einstein de dahil olmak üzere birç̧ok bilim insanı tarafindan yer yer sert eleştirilere uğrasa da, 20. yy. boyunca kuantum fiziği alanındaki başarılı gelişmelerle "kuantum fiziğinin kalbi" olarak nitelendirilmiştir [9]. 
Belirsizlik ilkesi de dahil olmak üzere, kuantum mekaniğindeki pek çok soyut kavram, bu alanda verilen kuantum fiziği ve modern fizik derslerinin zorluk düzeylerinin yüksek olarak algılanmasına yol açmaktadır. Bu alanda yapılan çalışmalarda [10] genel sonuç olarak, geleneksel bir yöntem olan düz anlatım yöntemi ile işlenen derslerde, öğrencilerin kuantum kavramlarını zor ve anlaşılmaz olarak gördükleri [11,12], bu kavramların yeterince etkili öğrenilemediği [13] ve derslerden yüksek notla geçilse bile öğrenilen kavramların kalıcı olmadığı belirtilmiştir $[14,15,16]$.

Bazı araştırmacılar [15], kuantum fiziği kavramlarına yönelik bu öğrenme yetersizliklerinin evrensel olduğunu, öğrencilerin yaşadıkları zorlukların ortak olduğunu ve bu zorluklara ileri düzey kuantum fiziği dersini alan öğrencilerde bile rastlandığını belirtmişlerdir. Çoğu öğrenci için, Heisenberg belirsizlik ilkesi de dahil olmak üzere pek çok kuantum fiziği kavramı, garip, esrarengiz, sadece soyut matematiksel formalizme dayanmış ve anlaşılması çok güç olarak nitelendirilmektedir [11]. Bunun sonucunda, öğrenciler birçok kavram yanılgısının etkisiyle, bu konularda çok düşük başarı sergilemektedirler [15,17-20]. $\mathrm{Bu}$ olumsuz algıların önüne geçerek, kuantum fiziği kavramlarının daha anlamlı ve kalıcı öğrenilmelerini sağlamak amacıyla, bu kavramların mümkün olduğunca görselleştirilerek ve somutlaştırılarak öğretilmeleri tavsiye edilmektedir [11-13,21-23]. 


\section{Araştırmanın Amacı ve Önemi}

Kuantum mekaniksel kavramların öğretilmesinde, somut materyal kullanımının daha rahat uygulanabileceği optik deneyleri kullanılabilir [9]. Fakat ilgili alanyazın incelendiğinde, kuantum fiziği ile ilgili ögrenme zorluklarının ve nedenlerinin belirlenmesinin ötesinde, bu sorunları aşmak için kullanılabilecek somutlaştırma örneklerine yeterince yer verilmediği görülmektedir. Pek çok kuantum mekaniksel olgunun, optik deneyleri ile yapılabileceği, [24] tarafindan ifade edilmiştir. Sıra değiştirme bağıntılarının deneysel olarak gösterimleri ile ilgili literatürde karşılaşılan örnek çalışmalarda [25,26,27,28,29], bu deneylerin, her öğrenci laboratuvarında kolaylıkla yapılamayacak kadar yüksek maliyetli ve zor erişilebilir oldukları görülmüştür.

$\mathrm{Bu}$ bağlamda bu çalışmanın amacı, üniversite öğrencileri tarafından öğrenilmesi zor olarak nitelendirilen ve Heisenberg belirsizlik ilkesi ile doğrudan ilişkili olan kuantum mekaniksel sıra değiştirme bağıntılarının, anlamlı ve kalıcı biçimde öğretilebilmesi için geometrik optik araçlarının kullanıldığı bir deney tasarlamaktır. Deneysel araçların seçiminde ekonomiklik ve kolay erişilebilirlik ölçütleri de göz önünde tutulmuştur. $\mathrm{Bu}$ çalışmada tanımlanan deneysel işlemlerin, tüm üniversitelerde, kuantum fiziği içerikli derslerin verildiği fizik, fizik öğretmenliği ve fen bilgisi öğretmenliği programları başta olmak üzere, tüm ilgili laboratuar uygulamalarında yapılabileceği ve teorik dersleri destekleyen gösteri deneyi formatında kullanılabileceği düşünülmektedir.

\section{Materyal ve Yöntem}

$\mathrm{Bu}$ çalışma kapsamında tasarlanan deneysel yöntem, üniversitelerin lisans düzeyinde verilen Modern Fiziğe Giriş ve Kuantum Fiziği derslerinde işlenen sıra değiştirme bağıntıları konusunun somutlaştırılarak öğretimini hedeflemektedir. Deney, nükleer fizik ve yüksek enerji fiziği alanlarında doktora eğitimi almış iki uzman tarafından tasarlanmış ve uygunluğu hakkında uzman görüşünü almak üzere, Prof. Dr. Abdullah Verçin'e başvurulmuştur. Yaklaşık 25 yıldır Ankara Üniversitesi, Fen Fakültesi, Fizik Bölümü'nde teorik fizik alanında çalışmalarda bulunan ve bu alanda yaygın olarak kullanılan bir Kuantum Mekaniği ders kitabının da yazarı olan Prof. Dr. Verçin, tasarlanan deneyin amaca hizmet edecek nitelikte olduğu onaylanmıştır. Makalenin ilerleyen bölümlerinde, deneysel işlemler ve matematiksel formalizm adım adım tanımlanmış olup, bu tanımlar ve formalizm, [8] ders kitabı esas alınarak yapılmıştır.

\section{Temel Kavramlar}

a) Dalga Fonksiyonu: Kuantum mekaniğinde bir sistemin en genel saf durumu, sistem hakkında tüm bilgiyi içinde barındıran karmaşı bir dalga fonksiyonu $(\psi(x))$ ile betimlenebilir. Dalga fonksiyonunun mutlak karesi, bu fonksiyonun temsil ettiği parçacığın, istenilen bir uzayda, herhangi bir anda ve belirli bir aralıkta bulunma olasılığını verir. Matematiksel olarak açıklamak gerekirse, parçacığın bir boyutta, a ile b noktaları arasında bulunma olasılığı, Denklem 1 ile verilir.

$P=\int_{a}^{b}|\psi|^{2} d x$

Örneğin, belirli bir hızla hareket edebilen bir elektron için dalga fonksiyonu, konum uzayında ve momentum uzayında farklı şekillerde yazılabilir. Aslında, kuantum mekaniksel 
olarak, konum ve momentum gözlenebilirleri, birbirlerinin Fourier dönüşümü olan, iki farklı uzayda temsil edilirler.

b) İşlemci: Kuantum mekaniğinde, belirlenen bir uzayda işlem yapan işlemciler (operatörler), herhangi bir fonksiyona etki ettiğinde, o fonksiyonu yine bir fonksiyona dönüştüren matematiksel ifadelerdir. İşlemciler, genellikle, üzerlerine $\left(^{\wedge}\right)$ işareti konularak gösterilirler. Örneğin, $\hat{\mathrm{d}}$ türev işlemcisinin, türevi alınabilen bir $f(x)$ fonksiyonuna uygulanması sonucu, ilgili fonksiyonun türevi elde edilir. Türev işlemcisi, matematiksel olarak, kısaca, Denklem (2)'de verildiği gibi gösterilebilir.

$\hat{d} f(x)=f^{\prime}(x)$

$\mathrm{Bu}$ çalışmada örneklenen kutuplama işlemcileri ( $\left.\hat{\mathrm{A}}_{\mathrm{i}}\right)$, kutupsuz olan doğal 1şı̆̆ın, istenilen bir yönde kutuplu hale getirilmesi işlemini gerçekleştiren işlemcilerdir.

c) Belirsizlik Bağıntıları: Kuantum mekaniği, mikroskobik parçacıklar ile ilgili bir fizik teorisi olduğundan, kuantum mekaniğine ait gözlenebilirler, ölçüm yapan araçlardan etkilenirler. Kuantum mekaniğinde gözlenebilirler, matematiksel olarak, Hermitesel işlemcilerle temsil edilirler [30]. Bu olgu en basit şekilde Heisenberg belirsizlik ilkesi ile açılanabilir [6]. Örnek olarak, x koordinatında konumun ve momentumun ölçümündeki belirsizlikler, sırasıyla $(\Delta \mathrm{x})$ ve $\left(\Delta p_{x}\right)$ ile gösterilebilir ve bu ikisi için Heisenberg belirsizlik bağıntısı, Denklem 3 ile verilir.

$$
\Delta \mathrm{x} \cdot \Delta p_{x} \geq \frac{\hbar}{2}
$$

Burada $\hbar$ indirgenmiş Planck sabiti $(h / 2 \pi)$, değeri $1,05457266 \times 10^{-34}$ joule.saniye olan temel eylem kuantumu olup, bir doğa sabitidir. Doğada, bu sabitten daha küçük hiçbir eylem gözlenemez. Denklem (3) ifadesine göre, konum ve momentumun ölçümündeki belirsizlikler çarpımı, bu temel sabitten daha küçük olamaz. Eğer herhangi bir sistem için bu çarpım, $\hbar$ 'dan çok büyükse, bu sistemi açıklamak için klasik fizik yasaları yeterlidir. Buna karşın, çarpımın mertebesi $\hbar$ ise, sistemi açıklamak için kuantum fiziği yasaları gereklidir.

d) Sıra Değiştirme Bağıntıları: Bir fizik deneyinde, sistem üzerinde birden fazla ölçüm alınmak istenebilir. Her bir ölçüm için farklı işlemciler kullanılabilir. Klasik mekanikten farklı olarak, kuantum mekaniğinde bazı işlemci grupları için, önce ya da sonra ölçüm almak önemlidir. Kuantum mekaniğindeki bu işlemcilerin, dalga fonksiyonuna farklı sıralarda uygulanmaları, farklı sonuçlar doğurur ve bu özellik $[\hat{\mathrm{A}}, \hat{\mathrm{B}}] \psi(x)=(\hat{\mathrm{A}} . \hat{\mathrm{B}}) \psi(x)-(\hat{\mathrm{B}} . \hat{\mathrm{A}}) \psi(x) \neq 0$ şeklinde gösterilebilir. Böyle işlemciler, birbirleriyle "sıra değiştiremez işlemciler" olarak isimlendirilirler. Bunun yanında, çarpım sırasının öneminin olmadığı, başka bir ifade ile $[\hat{\mathrm{A}}, \hat{\mathrm{B}}] \psi(x)=(\hat{\mathrm{A}} \cdot \hat{\mathrm{B}}) \psi(x)-(\hat{\mathrm{B}} \cdot \hat{\mathrm{A}}) \psi(x)=0$ koşulunu sağlayan işlemciler ise, birbirleri ile sıra değiştiren işlemciler olarak tanımlanırlar. Bu işlemcilerin dalga fonksiyonuna farklı sıralarda uygulanmaları, aynı sonucun elde edilmesi ile sonuçlanır.

Sura değiştirme bağıntıları, makroskobik dünyadan şu şekilde örneklenebilir: Birbirine dik iki eksen üzerinde herhangi bir $(a, b)$ koordinatında bulunan bir cismin, ardı ardına iki farklı yönde ötelenmesiyle $(c, d)$ noktasına ulaşması, ötelemelerin uygulanma sırasından bağımsızdır. Dolayısıyla bu farklı ötelemeler "sıra değiştirebilir" denir. Buna karşılık, cismin 
bu iki farklı eksen etrafinda ardı ardına döndürülmesi ise, döndürme eksenlerin sırasına bağlıdır ve bu döndürmeler "sıra değiştiremez" denir. Sıra değiştirme bağıntıları ile yukarıda belirtilen Heisenberg belirsizlik ilkesi arasında, doğrudan bir ilişki vardır [31]. Bu ilişki matematiksel olarak Denklem (4) ile gösterilebilir.

$$
\left\langle(\Delta \hat{\mathrm{A}})^{2}\right\rangle \cdot\left\langle(\Delta \hat{\mathrm{B}})^{2}\right\rangle \geq \frac{1}{4}|\langle\hat{\mathrm{A}} \cdot \hat{\mathrm{B}}-\hat{\mathrm{B}} \cdot \hat{\mathrm{A}}\rangle|^{2}
$$

$\mathrm{Bu}$ ifadeye göre, iki işlemcinin belirsizlikleri çarpımının alt sınırı, işlemcilerin sıra değiştirip değiştirmeyeceği ile ilişkilidir. Birbiriyle sıra değiştiren işlemciler, aynı anda ve kesin bir doğrulukla ölçülebilirken, birbiriyle sıra değiştiremeyen işlemciler, aynı anda ve kesin bir doğrulukla ölçülemez.

e) Işığın Kutuplanması: Bir elektromanyetik dalga olan ışık, birbirine dik eksenlerde salınım yapan, elektrik ve manyetik alanların bileşiminden oluşur. Elektromanyetik dalganın ilerleme doğrultusu, bu alanların salınım düzlemlerinin her ikisine de diktir. Genellikle, elektromanyetik dalganın kutuplanma (polarlanma) yönü, elektrik alan vektörünün ( $\vec{E}$ ) yönü olarak tanımlanır. Bir ışık kaynağından yayınlanan ışığın elektrik alan bileşeni, birden fazla farklı doğrultuda salınıyorsa, bu 1şık, kutuplanmamış 1şık olarak adlandırılır (Şekil 1.a). Bunun yanı sıra, ışığın elektrik alan bileşeninin tek bir salınım doğrultusu varsa, bu 1şık, belirli bir yönde kutuplu 1şık olarak adlandırılır (Şekil 1.c). Günlük hayatta karşılaşılan doğal 1şıklar, kutupsuzdur. Bu çalışmada, ışı̆̆ 1 kutuplu hale getirmek için, seçici soğurma yöntemine dayalı kutuplama yapan ve Şekil 1.b'de gösterilen optik kutuplayıcılar kullanılmıştır.

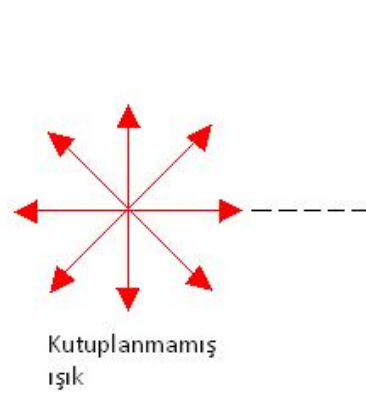

(a)

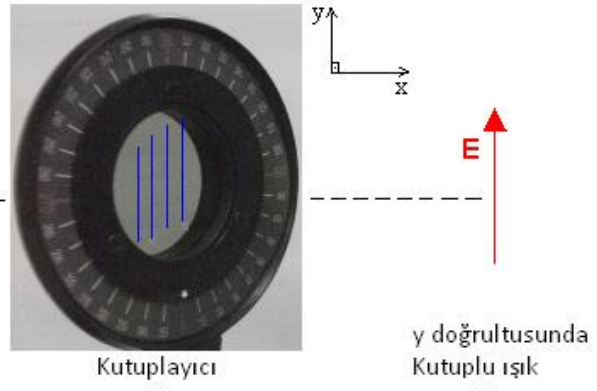

(b)

(c)

Şekil 1. Kutupsuz ışığın (a), y yönünde kutuplamaya ayarlı kutuplayıcı (b) kullanılarak, kutuplu (c) hale getirilmesi. (Kutuplayıcı üzerine çizilen mavi çizgiler, temsilidir)

Herhangi bir doğrultuda kutuplanmış olan 1şığın, bir kutuplayıcıdan geçmesi sonucu şiddeti, $\quad I=I_{0} \cos ^{2} \theta$ bağıntısına göre değişir. Burada $I_{0}$ ve $I$ sirasiyla, kutuplayıcıdan geçmeden önceki ve geçtikten sonraki 1şık şiddetleri, $\theta$ ise, 1şığın başlangıçtaki kutuplanma doğrultusu ile kutuplayıcı ekseni arasındaki açıyı göstermektedir. Malus Yasası olarak adlandırılan bu yasaya göre, herhangi bir doğrultuda kutuplanmış 1şık, kendi doğrultusuna tam olarak dik kutuplama eksenine sahip olan bir kutuplayıcıdan geçemez.

\section{Deneysel İşlemler}

Kuantum mekaniğindeki fiziksel işlemcilerin (operatörlerin) sahip olduğu sıra değiştirme bağıntılarının öğrencilere görsel olarak gösterilmesi amacıyla hazırlanan düzenek, Şekil 2'de verilmiştir. Düzenekte, 630-680 nm dalgaboyunda 1şık (elektromanyetik dalga) yayan diyot lazer, 0,1 ile 50.000 lüks ölçüm aralığında ve 0,1 lüks çözünürlüklü TT Technic 
VC1010A marka 1şıkölçer ve kutuplama açısı ayarlanabilen üç adet 1ş1k kutuplayıc1 kullanılmıştır. Kutuplayıcılar, lazer 1şık kaynağı ile 1şıölç̧er arasına, şekildeki gibi ardışık olarak yerleştirilmiştir. Tüm deney aşamaları, deney duyarlılığını yüksek tutmak amacıyla, lazer 1şık kaynağı haricinde herhangi bir 1şık kaynağının bulunmadı̆̆ gerçekleştirilmiştir. Harici ışık kaynaklarının da bulunduğu ortamlarda yapılacak deneylerde, deneyin gerçekleştirildiği andaki ışık arka fonunun tespit edilmesi ve arka fon düzeltmesinin yapılmas1 gerekmektedir.

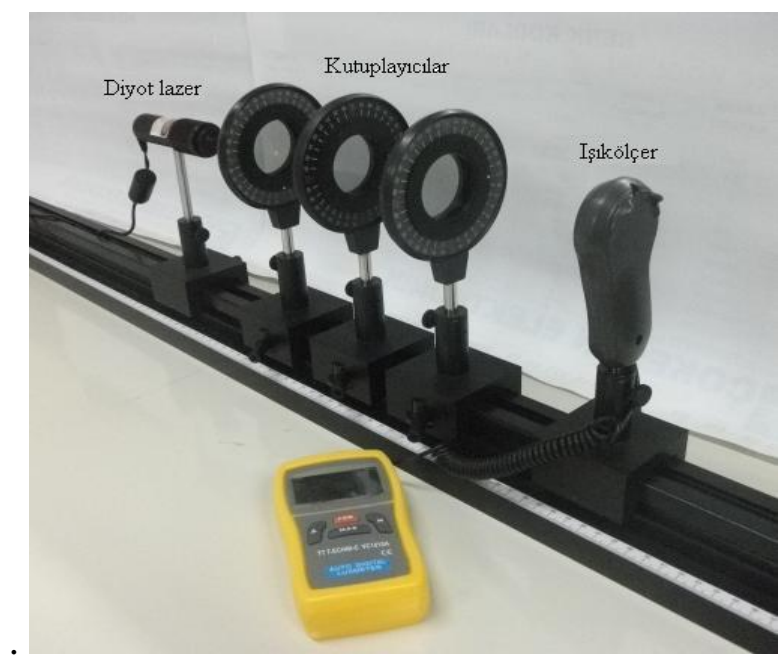

Şekil 2. Sıra değiştirme bağıntılarının temsili gösterimlerinin yapıldığı deney düzeneğinde, soldan sağa doğru; (i) 1şık kaynağı diyot lazer, (ii) 3 adet kutuplayıcı ve (iii) 1şıkölçer

İlk adımda, 1şık kaynağı ile 1şıkölçer arasına, birbirine dik kutuplama açılarında iki kutuplayıc1 ( $A_{1}$ ve $A_{3}$ kutuplayıcıları) yerleştirilir. Bu durumda, birbirine dik olacak şekilde ayarlanan her kutuplanma açısı için, kaynaktan çıkan 1şığın, 1şıkölçere hiç ulaşmadığı görülür. İkinci adımda ise, bu iki kutuplayıcı arasına, kutuplama açısı diğerlerinden farklı bir açıda olacak şekilde, üçüncü bir kutuplayıcı ( $\mathrm{A}_{2}$ kutuplayıc1sı) yerleştirilir. Bu durumda, 1şıkölçere bir miktar ışığın ulaştığı görülür.

Işık kutuplayıcılarının birer kuantum fiziksel işlemci olarak temsil edildiği sistemde, bu işlemcilerin sıra değiştirme bağıntılarını göstermek amacıyla, her kutuplayıcı bir işlemci olarak işaretlenmiştir. $0^{\circ}$ 'ye ayarlı (yatay kutuplama) $A_{1}$ kutuplayıcısı $\hat{A}_{1}$ işlemcisi ile, $90^{\circ}$ 'ye ayarlı (dikey kutuplama) $\mathrm{A}_{3}$ kutuplayıcısı $\hat{\mathrm{A}}_{3}$ işlemcisi ile ve yatayla $45^{\circ}$ açı yapacak şekilde ayarlı (köşegen kutuplama) $A_{2}$ kutuplayıcısı ise $\hat{A}_{2}$ işlemcisi ile temsil edilmiştir.

Tablo 1'de, bu üç kutuplayıcının, ışık kaynağı ve 1şıkölçer arasına farklı sıradaki yerleşimleri sonucu, 1şıölçerin ölçtüğü aydınlanma şiddetleri, lüks biriminde verilmiştir. Işıkölçere bir miktar 1şık ulaşması durumu " 1 " ile, hiç 1şık ulaşmaması durumu ise " 0 " ile temsil edilmiştir. Tablo 1'deki satır-1 ile satır-2 (veya satır-3)'deki aydınlanma şiddetleri değerleri karşılaştırıldığında, satır-1'de, 1şıkölçere 23 lüks 1şık ulaşmış (1 durumu) olmasına karşın, satır-2 (veya satır-3)'de hiç 1şık ulaşmadığ 1 (0 durumu) gözlenmiştir. Satır-2 (veya satır-3)'nin satır-1'den fark1, $\hat{A}_{2}$ ile $\hat{A}_{3}$ (veya $\hat{A}_{1}$ ) işlemcilerinin sıra değiştirmiş olmasıdır. Bu durum, $\hat{A}_{2}$ ile $\hat{A}_{3}$ (veya $\hat{A}_{1}$ ) işlemcilerinin sıra değiştiremez olduklarını göstermektedir. Matematiksel gösterimle, 


$$
\left[\hat{\mathrm{A}}_{2}, \hat{\mathrm{A}}_{3}\right] \neq 0 \text { veya }\left[\hat{\mathrm{A}}_{2}, \hat{\mathrm{A}}_{1}\right] \neq 0
$$

olduğu sonucuna varılır. Bu sıra değiştiremezliğin nedeni, birbirine dik kutuplama açılarında yerleşmiş işlemcilerin ardışık durumda bulunmalarının, 1şıölçere 1şık ulaşmasını engellemesidir.

Diğer yandan, yukarıda kurulan deney düzeneği ile, işlemcilerin sıra değiştirme bağıntılarını sağlamadıkları gösterildiği gibi, sıra değiştirme bağıntılarını sağladıkları da gösterilebilir. Tablo 1'de, satır-1 ile satır-4'de ölçülen aydınlanma şiddetleri (23 ve 106 lüks) karşılaştırılarak bu durum gözlenebilir. Satır-1 ile satır-4'ün birbirinden fark1, $\hat{A}_{1}$ ile $\hat{A}_{3}$ işlemcilerinin birbiriyle yer değiştirmiş olmasıdır. Her iki durumda da, ışıkölçere bir miktar 1şığın ulaşmış olması (1 durumları), bu iki işlemcinin, yani $\hat{A}_{1}$ ile $\hat{A}_{3}$ işlemcilerinin, sıra değiştirebileceklerini göstermektedir. Matematiksel ifade ile,

$$
\left[\hat{\mathrm{A}}_{1}, \hat{\mathrm{A}}_{3}\right]=0
$$

şeklinde ifade edilebilir. Birbirine dik kutuplama açılarına ayarlı $\hat{\mathrm{A}}_{1}$ ile $\hat{\mathrm{A}}_{3}$ işlemcilerinin aralarında farklı kutuplanma açısında yerleştirilmiş bir diğer işlemcinin varlığı, 1şıkölçere her iki durumda da bir miktar ışığın ulaşmasını sağlamaktadır.

İki işlemcinin sıra değiştirmediklerini gösterebilmek için, sadece bir durum yeterli iken, sıra değiştirdiklerini söyleyebilmek için ise, bütün durumlar incelenmelidir. $\mathrm{Bu}$ çalışmada, sadece bir durum için sıra değiştirme özelliği gösterilmesine rağmen, yöntem, diğer durumlara da aynen uygulanabilir. Fakat, çalışmanın nihai amacından sapmadan okuyucuyu sıkmamak için, sıra değiştirme bağıntılarının farklı durumlarda deneysel ispatının tekrarından kaçınılmıştır.

Çalışmada, bir lazer demetinin kutuplu ve kutupsuz durumları için sıra değiştirme bağıntıları incelenmiş olmasına rağmen, kuantum fiziksel olarak ışığın kutuplanma durumu, spini $1 / 2$ olan parçacık (fermiyon) durumlarıyla özdeşleştirilebilir. Bu yeni durumda, kutuplayıcıların yerini, parçacıkların spin yönelimlerini belirleyen mekanizmalar alır [28]. Bu tür sistemlere, kübit (qubit:quantum bit) sistemler denir [31].

Tablo 1. Farklı açılarda ardışık yerleştirilen üç kutuplayıcı durumunda, 1şıölç̧erin ölçtüğü aydınlanma şiddetleri

\begin{tabular}{clllcc}
\hline Dizilim No & \multicolumn{1}{c}{ İşlemcilerin dizilimi } & Aydinlanma şiddeti (lüks) & Durum \\
\hline Satır-1 & $\hat{\mathrm{A}}_{1}$ & $\hat{\mathrm{A}}_{2}$ & $\hat{\mathrm{A}}_{3}$ & 23 & 1 \\
Satır-2 & $\hat{\mathrm{A}}_{1}$ & $\hat{\mathrm{A}}_{3}$ & $\hat{\mathrm{A}}_{2}$ & 0 & 0 \\
Satır -3 & $\hat{\mathrm{A}}_{2}$ & $\hat{\mathrm{A}}_{1}$ & $\hat{\mathrm{A}}_{3}$ & 0 & 0 \\
Satır -4 & $\hat{\mathrm{A}}_{3}$ & $\hat{\mathrm{A}}_{2}$ & $\hat{\mathrm{A}}_{1}$ & 106 & 1 \\
\hline
\end{tabular}

\section{Matematiksel Gösterim}

Sıra değiştirme bağıntıların deneysel sonuçlarının matematiksel gösterimi, Dirac notasyonu kullanılarak yapılabilir. Buna göre, yatay kutuplama işlemcisi $\hat{\mathrm{A}}_{1}$ 'in, kutupsuz 1 şık durumuna uygulanması sonucu, $\hat{\mathrm{A}}_{1}$ : kutuplanmamış 1 şı $\rightarrow|Y\rangle$ işlemi ile, yatay kutuplu 1şık 
durumu elde edilir. Benzer olarak $\hat{\mathrm{A}}_{3}$ dikey kutuplama işlemcisinin, kutuplanmamış 1şık durumuna uygulanması, $\hat{\mathrm{A}}_{3}$ : kutuplanmamış 1şı $\rightarrow|D\rangle$ işlemi ile, dikey kutuplu 1şık durumu elde edilmesini sağlar. Son olarak, köşegen kutuplama işlemcisi $\hat{A}_{2}$ 'nin, kutuplanmamış ışı durumuna uygulanması ile, $\hat{\mathrm{A}}_{2}$ : kutuplanmamış 1şık $\rightarrow \frac{1}{\sqrt{2}}(|Y\rangle+|D\rangle)$, yatay ve düşey durumların çizgisel birleşimi olan köşegen kutuplu 1şık durumu elde edilir. Burada belirtilen $|Y\rangle,|D\rangle$ ve $(|Y\rangle+|D\rangle)$, sırasıyla, ışı̆̆ın yatay, dikey ve köşegen kutuplu durumlarına karş1lık gelmektedir.

$\hat{\mathrm{A}}_{1}, \hat{\mathrm{A}}_{2}$ ve $\hat{\mathrm{A}}_{3}$ işlemcilerinin sağladı̆̆ gibidir. Bu koşullara göre, $\hat{A}_{1}$ işlemcisinin, yatay kutuplu 1şığı tamamen geçirdiği, fakat dikey kutuplu 1şı̆̆ hiç geçirmediği, $\quad \hat{A}_{3}$ işlemcisinin, yatay kutuplu 1şı̆̆ 1 hiç geçirmediği, bunun yanında dikey kutuplu ışığı geçirdiği açıkça söylenebilir. $\hat{A}_{2}$ işlemcisi ise, üzerine gelen ışı̆̆g, yatay veya dikey kutuplu olması fark etmeksizin, bu iki durumun çizgisel birleşimi olacak şekilde kutuplayarak geçirdiği söylenebilir.

$$
\begin{aligned}
& \hat{\mathrm{A}}_{1}|Y\rangle=1|Y\rangle \text { ve } \hat{\mathrm{A}}_{1}|D\rangle=0|D\rangle \\
& \hat{\mathrm{A}}_{3}|Y\rangle=0|Y\rangle \text { ve } \hat{\mathrm{A}}_{3}|D\rangle=1|D\rangle \\
& \hat{\mathrm{A}}_{2}|Y\rangle=\frac{1}{\sqrt{2}}(|Y\rangle+|D\rangle) \text { ve } \hat{\mathrm{A}}_{2}|D\rangle=\frac{1}{\sqrt{2}}(|Y\rangle+|D\rangle)
\end{aligned}
$$

Bu tanımların ardından, Tablo 1'de deneysel olarak elde edilen sonuçların matematiksel ispatları, aşağıdaki şekilde yapılabilir. Yapılan işlemlerden de açıkça görülebileceği gibi, satır-2 ve satır-3'de, 1şıkölçere hiç 1şık ulaşmayacağı, diğerlerinde ise bir miktar ulaşacağ 1 matematiksel olarak gösterilmiştir. Böylece, $\hat{A}_{1}$ ile $\hat{A}_{3}$ işlemcilerinin birbirleriyle sira değiştirebileceği, fakat bunlardan her birinin $\hat{A}_{2}$ işlemcisi ile sıra değiştiremeyeceğinin ispatı tamamlanmış olur.

Satır-1: $\quad \hat{\mathrm{A}}_{1} \hat{\mathrm{A}}_{2} \hat{\mathrm{A}}_{3}:$ kutuplanmamış 1şı $\rightarrow \hat{\mathrm{A}}_{1} \hat{\mathrm{A}}_{2}|D\rangle=\frac{1}{\sqrt{2}} \hat{\mathrm{A}}_{1}(|Y\rangle+|D\rangle)=\frac{1}{\sqrt{2}}|Y\rangle$

Satır-2: $\quad \hat{\mathrm{A}}_{1} \hat{\mathrm{A}}_{3} \hat{\mathrm{A}}_{2}:$ kutuplanmamış 1ş1k $\rightarrow \frac{1}{\sqrt{2}} \hat{\mathrm{A}}_{1} \hat{\mathrm{A}}_{3}(|Y\rangle+|D\rangle)=\frac{1}{\sqrt{2}} \hat{\mathrm{A}}_{1}|D\rangle=0|D\rangle=0$

Satır-3: $\quad \hat{\mathrm{A}}_{2} \hat{\mathrm{A}}_{1} \hat{\mathrm{A}}_{3}:$ kutuplanmamış 1ş1k $\rightarrow \hat{\mathrm{A}}_{2} \hat{\mathrm{A}}_{1}|D\rangle=\hat{\mathrm{A}}_{2}(0|D\rangle)=0$

Satır-4: $\quad \hat{\mathrm{A}}_{3} \hat{\mathrm{A}}_{2} \hat{\mathrm{A}}_{1}:$ kutuplanmamış 1şık $\rightarrow \hat{\mathrm{A}}_{3} \hat{\mathrm{A}}_{2}|Y\rangle=\frac{1}{\sqrt{2}} \hat{\mathrm{A}}_{3}(|Y\rangle+|D\rangle)=\frac{1}{\sqrt{2}}|D\rangle$

\section{Sonuç ve Öneriler}

Kuantum mekaniğinin anlaşılmasında, işlemci formalizmi, sıra değiştirme bağıntıları ve Heisenberg belirsizlik ilkesi temel bir öneme sahiptir. Fakat teorik kuantum mekaniği içerikli derslerde bu kavramlar, daha çok geleneksel anlatım yöntemleri kullanılarak, 
uygulamada sınırlı kalınmasından dolayı, çoğu zaman yeterince anlaşılamamaktadır. Sonuçta, literatürde yer alan ve birbirini destekleyen birçok çalışmada $[11,12,13,14,15,16]$ ortaya konulduğu üzere, bu dersler öğrenciler açısından çok zor olarak nitelendirilerek, olumsuz bakış açıları geliştirilmekte ve çok düşük başarılar sergilenmektedir.

$\mathrm{Bu}$ çalışma kapsamında, öğrencilerin kuantum mekaniğindeki bu temel kavramları anlama düzeylerini artırmada kullanılabilecek deneysel bir yöntem önerilmiştir. Bu deneyi gerçekleştirmek için kullanılan düzeneğin, öğretim birimlerinde kolaylıkla erişilebilecek materyaller kullanılarak tasarlanmasına özen gösterilmiştir Bir deney seti için, deneysel malzemelerin ortalama maliyeti 100-200 TL arasındadır. Deneyin gösteri amaçlı gerçekleştirilmesinin yaklaşık olarak 10 dakika süre alacağı tahmin edilmekte olup, deneysel işlemler ve deney araçları, öğrencilerin güvenliği açısından herhangi bir risk oluşturmamaktadır.

$\mathrm{Bu}$ ve benzeri çalışmalar yolu ile soyut kavramlardan oluşan ve öğrenciler açısından öğrenme zorluğu çekilen kuantum fiziği kavramlarının, daha etkili ve kalıcı bir şekilde öğretilmesinde önemli aşamalar kaydedilebileceği düşünülmektedir. Bu çalışmalar sonucunda geliştirilecek etkin öğrenme materyalleri yoluyla, ülkemizin bilimsel gelişimine katk1 sağlayacak donanımlı bilim insanları ve öğretmenlerin yetiştirilmesine önemli katkılar sağlanmış olacaktır.

\section{Teşekkür}

Çalışmalarımız boyunca, değerli görüş ve önerilerini esirgemeyen sayın Prof. Dr. Abdullah Verçin'e teşekkür ederiz.

\section{KAYNAKLAR}

[1] Topdemir, H. G. ve Unat Y. (2008). Bilim Tarihi, Pegem Akademi Yayıncılık, Ankara.

[2] Newton, I. (1686). Philosophiae Naturalis Principia Mathematica (First Edition). Jussu Societatis Regiae ac Typis Josephi Streater, London.

[3] Yildırım, C. (2006). Bilim Tarihi, Remzi Kitabevi, İstanbul.

[4] Tekeli, S., Kahya, E., Dosay, M., Demir, R., Topdemir, H.G., Unat, Y. ve Aydın, A.K. (2009). Bilim Tarihine Giriş, Nobel Yayıncılık, Ankara.

[5] Gasiorowicz, S. (2003). Quantum Physics. John Wiley \& Sons Inc., United States of America.

[6] Heisenberg, W. (1927). Über den anschaulichen inhalt der quantentheoretichen kinematik und mechanick. Zeitschrift für Physik A Hadrons and Nuclei, 43, 172-198.

[7] Schrödinger, E. (1930). About Heisenberg uncertainty relation. arXiv:quant-ph/9903100v3 2008.

[8] Dereli, T. ve Verçin, A. (2009). Kuantum Mekaniği. TÜBA, Ankara.

[9] Pospiech, G. (2000). Uncertainity and complementarity: The hearth of quantum physics. Physics Education, 35(6), 393-399.

[10] Özdemir, E. ve Erol, M. (2011). Kuantum Fiziğinde Belirsizlik İlkesi: Hibrit Öğretimin Akademik Başarıya ve Kalıcılığa Etkisi, Buca Ĕ̈itim Fakültesi Dergisi, 29, 20-35.

[11] Çalışkan, S. ve Erol, M. (2002). Kuantum fiziği dersi harmonik osilatör konusu öğretim programı geliştirme üzerine bir çalışma. V. Ulusal Fen Bilimleri ve Matematik Eğitimi Kongresi (UFBMEK-5), ODTÜ, Ankara, 16-18 Eylül 2002.

[12] Özcan, Ö. (2011). Pre-service physics teachers' comprehension of wave function and operator concepts in quantum mechanics. International Journal of the Physical Sciences, 6(11), 2768-2775. 
[13] Didiş, N., Eryılmaz, A., \& Erkoç, Ş. (2010). Pre-service physics teachers' comprehension of quantum mechanical concepts, Eurasia Journal of Mathematics, Science \& Technology Education, 6(4), 227-235.

[14] Singh, C. (2001). Student understanding of quantum mechanics. American Journal of Physics, 69(8), 885-895.

[15] Singh, C., Belloni, M. \& Christian, W. (2006). Improving students' understanding of quantum mechanics. Physics Today, 59(8), 43-49.

[16] Zhu, G. \& Singh, C. (2012a) Improving students' understanding of quantum measurement I, Physical Review Special Topics - Physics Education Research, 8, 010117-1,8.

[17] Didiş, N., Özcan, Ö. ve Abak, M. (2008). Öğrencilerin bakış açısıyla kuantum fiziği: Nitel çalışma. Hacettepe Üniversitesi Eğitim Fakültesi Dergisi, 34, 86-94.

[18] Styer, D. F. (1996). Common misconceptions regarding quantum mechanics. American Journal of Physics, 64, 31-34.

[19] Şen, A. İ. (2002). Fizik öğretmen adaylarının kuantum fiziğinin temeli sayılan kavram ve olayları değerlendirme biçimleri, Ballkesir Üniversitesi Fen Bilimleri Enstitüsü Dergisi, 4(1), 76-85.

[20] Yıldız, A. ve Büyükkasap, E. (2011). Öğretmen adaylarının belirsizlik ilkesini anlama düzeyleri ve öğrenme amaçlı yazmanın akademik başarıya etkisi, Türk Fen Eğitimi Dergisi (TÜFED), 8(4), 134-148.

[21] Kohnle, A., Douglass, M.M., Edwards, T.J., Gillies, A.D., Hooley, C. \& Sinclair, B.D. (2010). Developing and evaluating animations for teaching quantum mechanics concepts. European Journal of Physics, 31(6), 1441-1455.

[22] Rebello, N. S. \& Dean Zollman, D. (1999). Conceptual understanding of quantum mechanics after using hands-on and visualization instructional materials, National Association for Research in Science Teaching (NARST), March 1999.

[23] Zhu, G. \& Singh, C. (2012b) Improving students' understanding of quantum measurement II, Physical Review Special Topics - Physics Education Research, 8, 010118-1,13.

[24] Reck, M., Zeilinger, A., Bernstein, H.B \& Bertani, P. (1994). Experimental realization of any discrete unitary operator. Physical Review Letters, 73-1, 58-61.

[25] Hasegawa, Y., Menhart, S., Meixner, R. \& Badurek, G. (1997). Noncommutation of Pauli spin operators in neutron polarimetry. Physics Letters A, 234, 322-328.

[26] Kim, M.S., Jeong, H., Zavatta, A., Parigi, V. \& Bellini, M. (2008). Scheme for proving the bosonic commutation relation using single-photon interference. Physical Review Letters 101, 260401.

[27] Zavatta, A., Parigi, V., Kim, M.S., Jeong, H. \& Bellini, M. (2009). Experimental demonstration of the bosonic commutation relation via superpositions of quantum operations on thermal light fields. Physical Review Letters, 103, 140406.

[28] Kim, Y-S., Lim, H-T., Ra, Y-S. \& Kim, Y-H. (2010). Experimental verification of the commutation relation for Pauli spin operators using single-photon quantum interference. Physics Letters A, 374, 4393-4396.

[29] Yao, X-C., Fiurasek, J., Lu, H., Gao, W-B., Chen, Y-A., Chen, Z-B. \& Pan, J-W. (2010). Direct experimental verification of quantum commutation relations for Pauli operators. arXiv:quant-ph/1002.1613v1.

[30] Verçin, A. (2012). 85 yıl sonra belirsizlik bağıntıları. Fizik Dünyası Dergisi, 10.11.2012 tarihinde http://fizikdunyasi.ankara.edu.tr/j/ adresinden alınmıştır.

[31] Sakurai, J.J. (1994). Modern Quantum Mechanics (Revised Edition). AddisonWesleyPub. Co. 